\title{
TEMPERATURE DEPENDENCY OF FRACTURE TOUGHNESS OF HIGH-STRENGTH FERRITIC STEEL HARDOX-400
}

\author{
Ihor DZIOBA ${ }^{*}$, Robert PAŁA ${ }^{*}$ Tadeusz PAŁA \\ *Department of Machine Design Fundamentals, Faculty of Mechatronics and Machine Design, Kielce University of Technology, \\ Al. 1000-lecia PP 7, 25-314 Kielce, Poland \\ pkmid@tu.kielce.pl, probertrobert@gmail.com, tadeusz.pala@gmail.com

\begin{abstract}
The paper presents experimental results of the changes of strength and fracture toughness characteristics of high-strength ferritic steel Hardox-400 in the temperature range from $-100 \mathrm{OC}$ to $+20 \mathrm{OC}$. It has been shown that the strength characteristics values increase linearly with lowering the temperature. Changes of fracture toughness characteristics from temperature are more complex and they are dependent on thickness of the tested specimens.
\end{abstract}

Key words: High-Strength Ferritic Steel, Strength Characteristics, Fracture Toughness, Master Curves

\section{INTRODUCTION}

Ferritic steels are used for construction elements in various industries - construction in building, energetics, construction machinery and other. The widespread use of ferritic steels requires knowledge of strength characteristics and fracture toughness in temperature ranges in which they are going to be operated. Extensive studies of ferritic steels characteristics of yield stress value $200<\sigma_{y}<820(\mathrm{MPa})$ have been carried out by Wallin with his cooperators (ASTM E 1820-05, 2000; Wallin et al., 1984, 2004; Wallin, 1984, 2002)). Accordingly to the researches, the dependencies of the change of strength characteristics, impact and fracture toughness from the temperature have been determined. The conception of the Master Curve determination has been presented, which allows to evaluate fracture toughness in ferritic steel in areas of low plateau and transition region. On the basis of the proposed concept, the standard ASTM E1921 has been worked out (ASTM E1921-05, 2005). The concept of Master Curve was also used in the procedures of evaluation strength of the construction elements SINTAP (1999) and FITNET (FITNET, 2008; Neimitz et al., 2008).

Modern technologies allow to perform ferritic steel products, in which the yield strength is significantly higher than $\sigma_{y}=820 \mathrm{MPa}$. Therefore, the question arises whether the concept of the Master Curve prepared on the basis of the traditional ferritic steels can be directly applied to the modern, high- strength ones? Based on the researches carried out on the steel specimens S960Q $\left(\sigma_{y}>960 \mathrm{MPa}\right)$, it has been stated that certain modifications should be implemented during preparation of the Master Curve for this steel [5].

In this article, the experimental results obtained during tests of steel Hardox- 400 have been presented. The influence of the tests temperature in the range from -100 to $+20{ }^{\circ} \mathrm{C}$ on the strength characteristics and fracture toughness of different thickness specimens have been shown.

\section{MATERIAL, RESEARCH METHODS}

Steel Hardox-400 is a low alloy steel of ferritic matrix. Chemical composition is given in Tab. 1. During the manufacture of steel it is thermo-mechanically treated to give the microstructure of tempered bainite-martensite (Fig. 1) having a hardness of about $400 \mathrm{HV}$. Specimens $(12 \times 24 \times 116 \mathrm{~mm})$ were cut out of the plate of $30 \mathrm{~mm}$ thickness. Hardness distribution in the direction of the plate thickness is shown in the figure 2a. Since the hardness varies in thickness, the specimens for determining the fracture toughness, SENB were cut so, that the initial crack tip was located in the centre of the thickness plate (Fig. 2b). Specimens for the uniaxial tension test to determine the characteristics of the material were also collected from the central part of the plate.

Tab. 1. Chemical composition of the steel Hardox-400 (in mas. \%)

\begin{tabular}{|c|c|c|c|c|c|c|c|c|c|}
\hline & $\mathbf{C}$ & $\mathbf{S i}$ & $\mathbf{M n}$ & $\mathbf{P}$ & $\mathbf{S}$ & $\mathbf{C r}$ & $\mathbf{N i}$ & $\mathbf{M o}$ & $\mathbf{B}$ \\
\hline $\begin{array}{c}\text { Hardox- } \\
400\end{array}$ & 0.12 & 0.52 & 1.25 & 0.01 & 0.001 & 0.66 & 0.04 & 0.012 & 0.001 \\
\hline
\end{tabular}

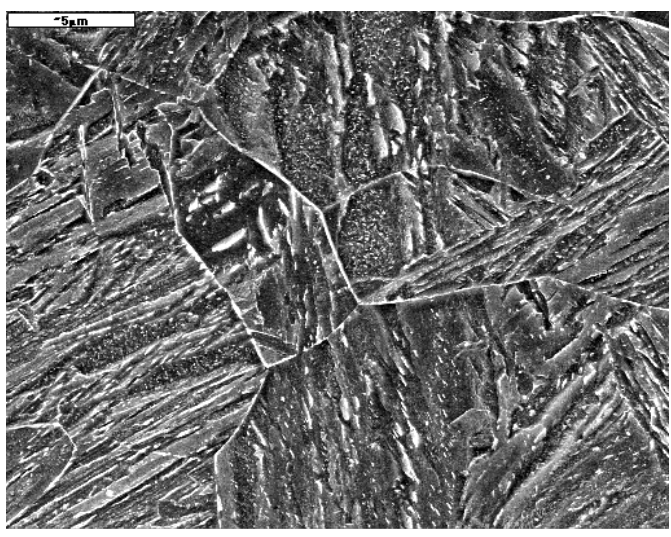

Fig. 1. The microstructure of the steel Hardox-400, 5000x 
(b)
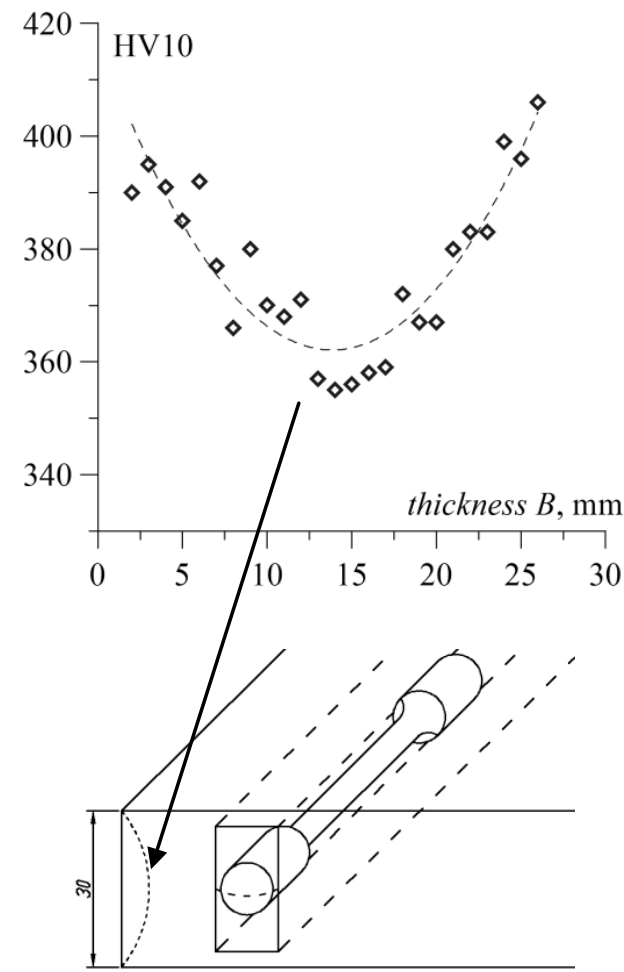

Fig. 2. a) hardness distribution along the thickness of the plate; b) the scheme of cutting uniaxially tensioned specimens and threepoint bend specimens

The researches were carried out on the universal testing machine MTS-250 equipped in the automated control system and data record in the temperatures range from $-100^{\circ} \mathrm{C}$ to $+20^{\circ} \mathrm{C}$. The tests in the minus temperatures were carried out in a thermal chamber in the evaporated nitrogen environment. The accuracy of maintaining the desired temperature during the test was $\pm 0.5^{\circ} \mathrm{C}$. The uniaxial tension tests were carried out on standard fivefold specimens. The signals of force, $P$, and elongation of the measuring part of the specimen, $u$, were recorded in real time.

Fracture toughness characteristics were determined on the three-points bend specimens with one-side notch (SENB, $12 \times 24 \times 110 \mathrm{~mm}, a_{0} / W=0.5$ ) according to the standard ASTM E1820-05 [1]. The signals of force, $P$, specimen deflection at the load point, $u_{\text {ext }}$, crack opening, $u_{C O D}$, and potential change, $U$, were recorded during fracture toughness determination. In the case of ductile fracture mechanism, the critical value of $\mathrm{J}$ integral, $J_{I C}$, was determined on each single specimen using the potential change method to determine the crack growth and to draw up the

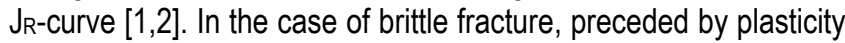
area in front of the crack tip, the critical value of the $\mathrm{J}$ integral, $\mathrm{J}$, was calculated according to the formula:

$$
\mathrm{J}_{\mathrm{C}}=\frac{2 \mathrm{~A}_{\mathrm{C}}}{\mathrm{B}\left(\mathrm{W}-\mathrm{a}_{0}\right)}
$$

where: $A_{c-}$ is deformation energy at the moment of cracking, calculated on a basis of the graph $P=f\left(u_{\text {ext }}\right)$; $a_{0}$ is total crack length, notch plus fatigue pre-crack. The critical values of the $\mathrm{J}, \mathrm{J}_{\mathrm{C}}$ integral were converted into units of the stress intensity factor:

$K_{J C}=\sqrt{\frac{J_{I C} E}{\left(1-v^{2}\right)}}$

where: $E$ is Young's modulus, $v$ - is Poisson's ratio.

\section{STRENGTH CHARACTERISTICS}

Sample graphs for the testing temperature $T=-20^{\circ} \mathrm{C}$ of the stress-strain curves $(\sigma-\varepsilon)$ are shown in the figure 3 . The graphs of the real $\sigma-\varepsilon$ were made to the moment where becomes apparent a maximum force value, taking into account the constant volume of the measuring part of the specimen.

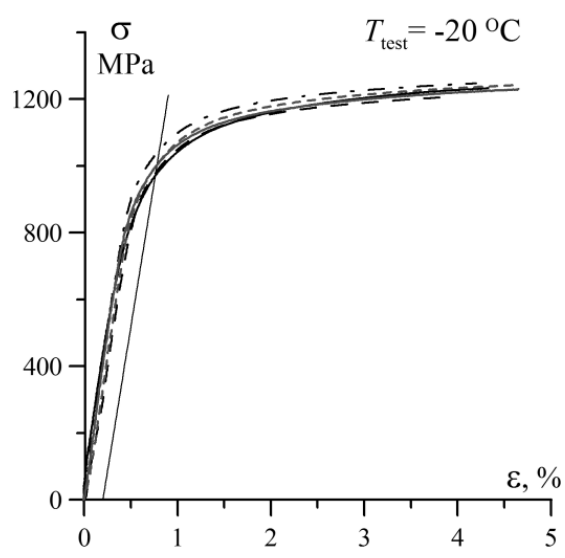

Fig. 3. The example of a $\sigma-\varepsilon$ graphs for the steel Hardox- 400

(a)

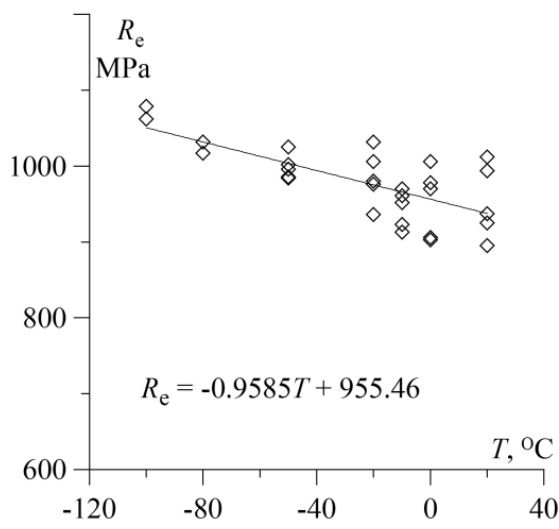

(b)

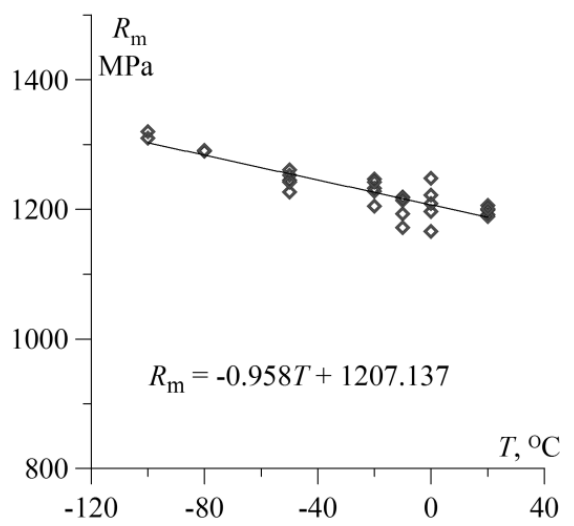

Fig. 4. The change of the strength characteristics depending on the test temperature: a) $\left.R_{\mathrm{e}} ; b\right) R_{\mathrm{m}}$

In Fig. 4, are shown tendencies of the change of strength characteristics, $R_{\mathrm{e}}$ and $R_{\mathrm{m}}$, from the test temperature: increase of these values with lowering the temperature causes. This in- 
crease is steady, it can be shown by means of the linear function. The largest data scatter was observed in the temperature range $[-20 ;+20]^{\circ} \mathrm{C}$. The change tendencies of the Young's modulus, $E$, strain values for steady extension, $\varepsilon\left(R_{\mathrm{m}}\right)$ and the values of total relative extension $A_{5}$ are similar. For all these values was noted increase together with lowering the temperature, which can be described by means of linear functions:

$R_{e}=-0.9585 T+955.46$

$R_{m}=-0.9585 T+1207.137$

$E=-0.00912 T+181.085$

$\varepsilon\left(R_{m}\right)=-0.011 T+4.297$

$A_{5}=-0.0185 T+15.718$

Only the values of relative restrict of the cross-section of the specimen slightly decrease with lowering the temperature.

\section{FRACTURE TOUGHNESS}

Critical values of fracture toughness were determined on the specimens of the thickness $B$, from 1 to $24 \mathrm{~mm}$ in the temperatures range $[-100 ;+20]{ }^{\circ} \mathrm{C}$. KJc changes depending on the test temperature of the selected thickness of the tests are shown in Fig. 5. Similarly, as for the strength characteristics for fracture toughness, has large scatter of data. The largest data scattering occurs in the transition region, where cracking mechanism changes from the cleavage fracture to the plastic one (Fig. 5). Fig. 6a presents dependencies of the critical value of fracture toughness $K_{\mathrm{Jc}}$ from temperature for the specimens of thickness from the range $1 \div 12 \mathrm{~mm}$. The fracture toughness was determined on specimens with thickness $B \geq 8 \mathrm{~mm}$ generally gradually decreases slightly with increasing thickness for the corresponding test temperature (Fig. 6a). For thickness $B \leq 4$ critical values of fracture toughness remain almost constant level to a certain temperature, then $K_{\mathrm{Jc}}$ were decreases, caused by changes in the mechanism of crack propagation from plastic to ductile-brittle. In the specimens of thickness $B=4 \mathrm{~mm}$ the decrease of fracture toughness was observed at the temperatures lower than $-10^{\circ} \mathrm{C}$. Reduction in thickness also lowers the temperature at which the crack propagation mechanism changes. For specimens of the thickness $B \leq 2 \mathrm{~mm}$ is a temperature lower $-50^{\circ} \mathrm{C}$.

Fig. $6 \mathrm{~b}$ presents the change dependencies of the fracture toughness critical value, $K_{\mathrm{Jc}}$, on $B$ thickness. Dependency course points to the irregular change shape $K_{\mathrm{Jc}}$ from $B$ at each tested temperature. In the dependencies for a suitable temperature occurs a maximum achieved at some thickness characteristic. From the maximum point, Kuc values decrease with the specimen thickness. Reducing the thickness of the specimen below value, at which the maximum occurs, causes a rapid reduction in the critical value of fracture toughness. With increasing thickness of the specimen, above the corresponding maximum, the $K_{\mathrm{Jc}}$ values also reduce, but less rapidly. Along with the lowering of the test temperature, dependencies are located below, maintaining its characteristic shape, and maximum point descends and moves towards the thickness reduction side. (a)

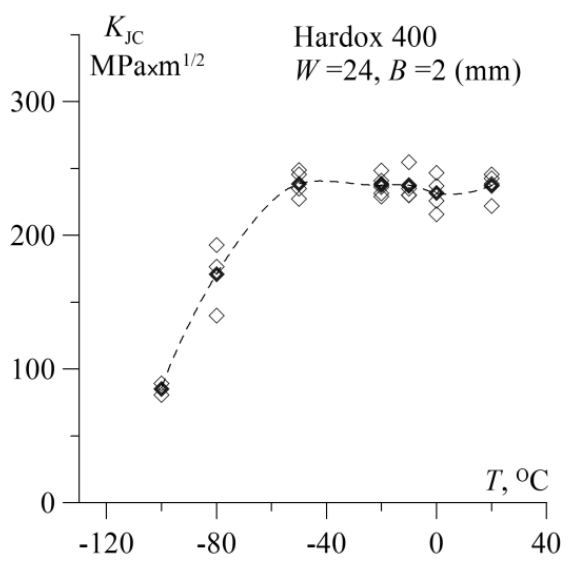

b)

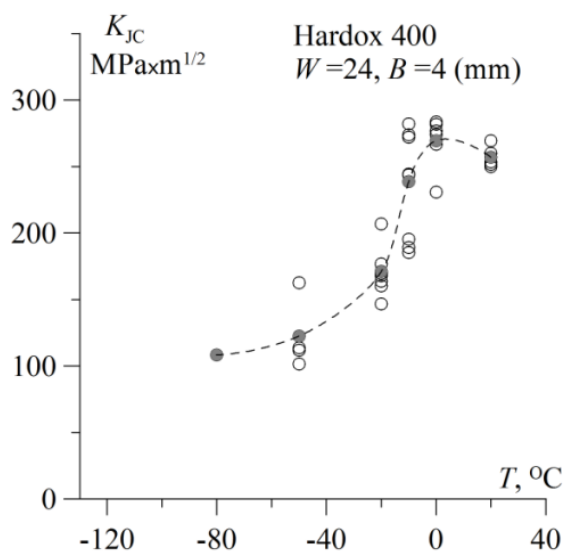

(c)

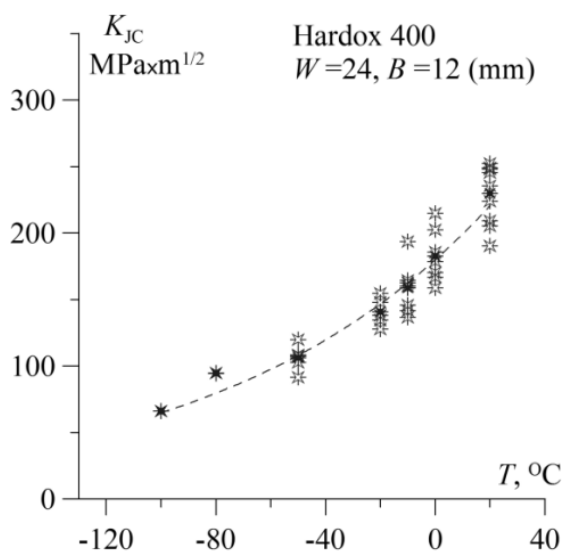

Fig. 5. $K_{\mathrm{Jc}}-T$ dependency for the specimens of thickness $B$ : a) $2 \mathrm{~mm}$; b) $4 \mathrm{~mm}$; c) $12 \mathrm{~mm}$

Specimen thickness, $B$, necessary for the dominance of plane strain during determination of $K_{\mathrm{IC}}$ critical value, is determined from the dependence (ASTM E 1820-05, 2000):

$B \geq B_{K}=2.5\left(\frac{K_{C}}{\sigma_{y}}\right)^{2}$

However, the plane strain dominance during JIC determination is assured for the specimens of the $B$ thickness, determined from the connection (ASTM E 1820-05, 2000):

$B \geq B_{J}=\alpha \frac{J_{C}}{\sigma_{y}}$ 
In the formulas (8) and (9) $\sigma_{\mathrm{y}}$ is yield stress, $\alpha=25$ for the bent specimens or $\alpha=175$ for the tensioned specimens.

(a)

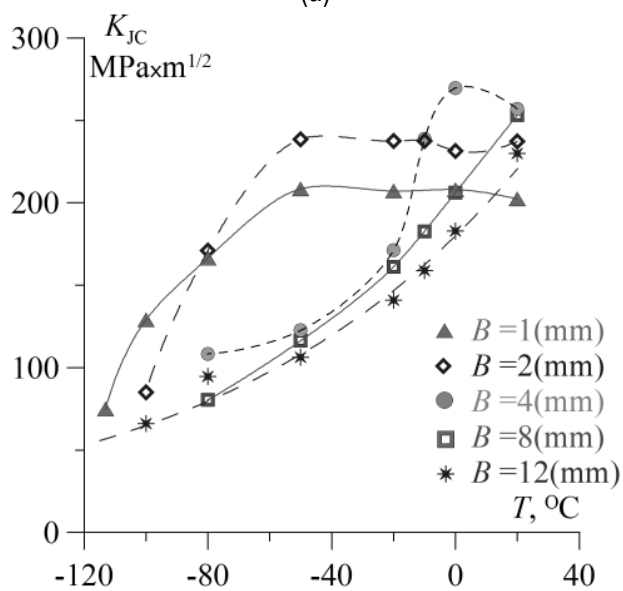

(b)

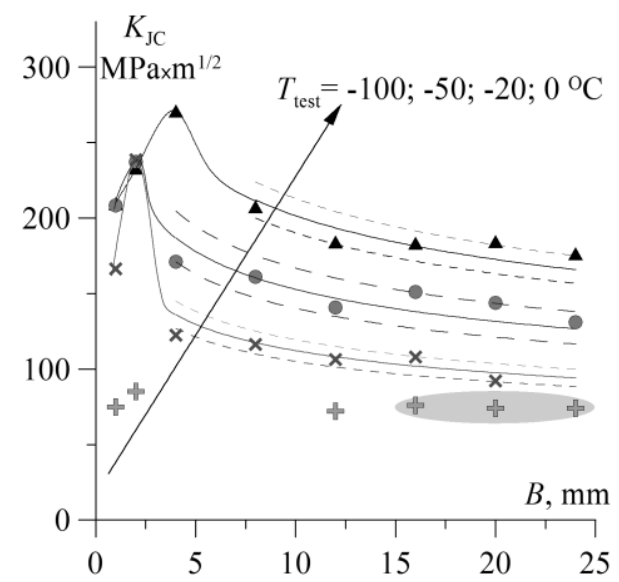

Fig. 6. Kuc dependencies: a) on the $T$ test temperature for specimens of various thickness $B ; b$ ) on thickness $B$ for the various T

Differences of specimens thickness required according to the conditions (8) and (9) are big: $B_{J} / B_{K} \approx 15 \div 60$. From all specimens presented in the article, the condition (8) satisfies only specimens of the thickness $B>16 \mathrm{~mm}$, tested at the temperature $T=-100{ }^{\circ} \mathrm{C}$ (shaded area in the Fig. $6 \mathrm{~b}$ ). There is much more specimens, which thickness corresponds to the condition (9). For the test temperature $T=0^{\circ} \mathrm{C}$ are specimens of thickness $B \geq 8 \mathrm{~mm}$, for $T=-20$ and $-50^{\circ} \mathrm{C}$ are specimens $B \geq 4 \mathrm{~mm}$

The dependencies shown in the fig. $6 \mathrm{~b}$ indicate that the critical value of fracture toughness, $K_{s c}$, is not constant value, $K_{s c}$ decreases along with specimen thickness increase. On the basis of statistical researches for ferritic steels $\left(\sigma_{y}<820 \mathrm{MPa}\right)$ has been proposed formula, which describes the change of the $K_{\mathrm{Jc}}$ on the specimen thickness, $B$ (ASTM E1921-05, 2005; Wallin et al., 2004, Wallin, 2002):

$K_{J C\left(B_{1}\right)}=K_{\min }+\left(\frac{B_{2}}{B_{1}}\right)^{\frac{1}{4}}\left(K_{J C\left(B_{2}\right)}-K_{\text {min }}\right)$

where: $\mathrm{K}_{\mathrm{JC}\left(\mathrm{B}_{1}\right)}$ and $\mathrm{K}_{\mathrm{JC}\left(\mathrm{B}_{2}\right)}$ are the critical values of fracture toughness for the specimens of thickness $B_{1}$ and $B_{2}\left(B_{1}>B_{2}\right)$, respectively; $K_{\min }$ is the minimum critical value of fracture tough- ness for ferritic steel, $\mathrm{K}_{\min }=20 \mathrm{MPa} \cdot \mathrm{m}^{1 / 2}$ (ASTM E1921-05, 2005; Wallin et al., 2004, Wallin, 2002).

The change dependency KJC on B in the range, where the condition (9) is satisfied, was described by means of the function (10) (solid lines on the graph Fig. 6b). The dashed line shows the spaces in which are located the dispersions towards the central trend, they do not exceed $\pm 10 \%$.

\section{SUMMARY}

As a result of the research it has been shown that the strength characteristics $R_{\mathrm{e}}$ and $R_{\mathrm{m}}$, Young's modulus, $E$, strain values for steady extension, $\varepsilon\left(R_{\mathrm{m}}\right)$, and the values of total relative extension, $Z$, increase along with lowering the research temperature. Change of these values can be described by means of the linear function ((3)-(7) formulas). Changes of fracture toughness characteristics from temperature are more complex and they are dependent on thickness of the tested specimens. In thickness range of the specimens, which satisfies the condition (9), fracture toughness dependency on thickness for a chosen temperature can be described by the function of type (10). Results, contained in this article, are the first part of a larger research aimed at experimental-numerical analysis of the steel cracking process including microstructural factors.

\section{REFERENCES}

1. ASTM E 1820-05 (2000), Standard Test Method for Measurement of Fracture Toughness. ASTM; Philadelphia.

2. ASTM E1921-05 (2005), Test Method for Determination of Reference Temperature $T_{0}$ for Ferritic Steels in the Transition Range, ASTM, Philadelphia.

3. FITNET (2008), Fitness - for - Service. Fracture - Fatigue - Creep Corrosion, Edited by M. Koçak, S. Webster, J.J. Janosch, R.A. Ainsworth, R. Koerc.

4. Neimitz A., Dzioba I., Graba M., Okrajni J. (2008), Assessment of the strength, durability and safety of the structural components containing defects, Kielce University of Technology (in Polish).

5. Neimitz A., Dzioba I., Limnell T. (2012), Master Curve of ultra high strength steel, International Journal Pressure Vessels and Piping; Vol. 92,19-26.

6. SINTAP (1999), Structural Integrity Assessment Procedure for European Industry, Project No Be95-1426, British Steel.

7. Wallin K, Nevasmaa P, Laukkanen A, Planman T. (2004), Master Curve analysis of inhomogeneous ferritic steels, Engineering Fracture Mechanics; Vol.71, 2329-2346.

8. Wallin K. (1984), The Scatter in KIC Results, Engineering Fracture Mechanics. Vol. 19, 1085-1093.

9. Wallin K. (2002), Master curve analysis of the "Euro" fracture toughness dataset, Engineering Fracture Mechanics; Vol. 69, 451-481.

10. Wallin K., Saario T., Törrönen K. (1984), Statistical Model for Carbide Induced Brittle Fracture in Steel, Metal Science, Vol.18, 13-16.

The work has been accomplished under the research project No. 501 199640 financed by the Scientific Research Committee. 